\title{
Editorial
}

\section{El Guanacaste Nicoyano y los "Anti-viejos"}

\author{
Inés Revuelta Sánchez, M.B.A. \\ Académica \\ Facultad de Ciencias de la Salud \\ Universidad Nacional \\ Escuela de Ciencias del Movimiento Humano y Calidad de Vida \\ inesrevuelta@gmail.com
}

Hace unos meses, observé con mucha tristeza como un hermoso árbol de Guanacaste ubicado al frente de la Iglesia de Nicoya, era talado sin piedad ni misericordia. Los responsables de la toma de decisión de semejante acto, adujeron que la misma se fundamentaba porque las raíces del poderoso árbol estaban destruyendo una calle que pasaba enfrente.

En ese momento y ante tan primitiva justificación (¡de las muchas que se escuchan en estos tiempos!), no pude evitar pensar en la historia del huevo y la gallina: ¿quién vino primero? En este caso, no tengo la más mínima duda de que el centenario árbol estuvo antes que la asfaltada calle pero esto pareciera no haber sido importante en el momento de tomar la decisión.

Más de cien años de historia, en un solo día se vinieron al suelo. Más de cien años de darle cobijo y sombra a madres con sus bebés, escolares, colegiales, parejas de enamorados, adultos mayores, trabajadores en su camino de ida y regreso o simples transeúntes; todos amparados por este personaje que bajo sol y lluvia se mantuvo fuerte y seguro, se vinieron abajo sin mayor consideración por la mano del hombre. En menos de un día se esfumaron más de cien años de majestuosidad producto de la naturaleza y de la mano de Dios. En menos de un día se acabaron más de cien años de darle posada a otras especies animales. ¡En fin!, pareciera que los responsables hicieron suyo aquella frase que dice," ique cien años no son nada!"

La realidad es que toda la historia, la herencia, la fortaleza de un árbol que indudablemente llegó a formar parte no sólo de la belleza escénica sino de la herencia histórica de este hermoso lugar, pasaron a segundo plano y lo más sencillo fue cortar de tajo (literalmente) con el árbol que estaba impidiendo el desarrollo y se les estaba"atravesando" a la calle Pero, ¿quién estuvo primero? ¿Quién se le"atravesó" a quién? $\mathrm{O}$, ¿quién será el atravesado? 
Y lo cierto es que más allá del pobre Guanacaste y las múltiples razones que se podrían enunciar para condenar semejante acto, me queda la triste impresión de que entre ese pobre árbol y lo que estamos viviendo en estos tiempos de modernidad hay un paralelismo imposible de ignorar.

El talar un árbol centenario sin ninguna consideración por lo menos en lo que respecta a su edad y su valor, es un reflejo de una situación que estamos viviendo cada vez con más frecuencia. Es este el reflejo de un mal que aqueja a nuestra sociedad : lo viejo cada vez es más temido, despreciado y maltratado. Basta con que uno pregunte la edad de algo o alguien para que se forme una opinión estereotipada de si ese alguien o algo tiene mayor utilidad. Esto ha derivado en la conformación de un grupo social el cual se podría nombrar como las y los "anti-viejos".

Las y los "anti-viejos" abundan en todas partes y son peores de lo que parecen: desacreditan, destruyen, desprecian y desconocen el valor de cada persona basándose en su edad. Abundan en lo público y en lo privado, se esconden en las redes sociales o hacen chota en público como si sus chistes anti-edad fueran candidatos a un Nobel de la Comicidad.

Sin verse en el espejo y sin considerar que todos envejecemos un día a la vez, a partir del primer día de nuestra vida e incluso antes ya que envejecemos dentro del vientre materno, las y los "anti-viejos" probablemente se consideran a sí mismos como eternos superhéroes y heroínas destinados a vivir eternamente sólo porque sí. La frase "i iporta a mí! " la llevan hasta el extremo cuando ven a otros sin observarse ellas y ellos en el espejo porque pareciera que el rechazo a envejecer es precisamente un reflejo de su miedo a ser viejas y viejos.

Es así como los "anti-viejos" conforman una secta secreta que da paso a multitudes que en forma inconsciente y subconsciente ven con indiferencia, miedo y hasta verdadero desprecio, a todo lo que sea viejo o aunque sea en forma leve, se le parezca.

Las y los "anti-viejos" están en todos lados y donde uno menos espera. Es tanto el bombardeo publicitario y en medios de comunicación en contra de lo viejo y de lo que el envejecer conlleva, que cada día se están convirtiendo en más y más las y los adeptos a esta corriente de pensamiento enajenante.

Las y los "anti-viejos", han perfeccionado un lenguaje en el cual los términos envejecer, vieja, viejo, ancestros, adultos mayores y hasta abuelo y abuela, son tabú y dan paso a mucha manipulación social. Desarrollan técnicas de comunicación bastantes efectivas que se basan no sólo en el lenguaje oral sino también en lo corporal para rechazar cualquier cosa que recuerde, evoque, sugiera o indique el paso de los años. Estas técnicas se transmiten de generación en generación aunque en el proceso nieguen y renieguen del principio del envejecimiento y es así como pretenden que no envejecen principalmente amparándose a la máxima de "no lo acepto, ergo, no sucede." 
$\mathrm{Al}$ ir desarrollando estas técnicas y estrategias de comunicación, se van multiplicando. Es así como poco a poco las y los "anti-viejos" se van reproduciendo cual película de zombis y si no nos cuidamos, en cualquier momento, hasta el más preparado para enfrentárseles, se convierte en uno de ellos. Y es que verdaderamente es una corriente poderosa y pegajosa que no encuentra mayor oposición en ninguna parte porque al fin de cuentas, envejecer sigue siendo sinónimo de deterioro, pérdida y muerte.

Las y los "anti-viejos" han conseguido infiltrarse a todo nivel y eso está provocando una epidemia viral con consecuencias más serias de lo que muchas y muchos pudieran pensar. En escuelas y colegios probablemente no hay un enfoque específico sobre el tema del envejecimiento y su relación con la calidad de vida desde un punto de vista propositivo. Mucho menos se relaciona este tema con los valores de los cuales tanto hablamos en nuestra sociedad, por lo que las y los estudiantes que recibimos en la Universidad, vienen con el "chip anti-viejos" incorporado. Esto es una verdadera lástima porque todas y todos los educadores sabemos que cuesta más eliminar un defecto aprendido que trabajar y formar un hábito o conducta en un lienzo en blanco.

Más allá de la comunidad universitaria, el enfoque del pensamiento "anti-viejos" tiene repercusiones serias a nivel individual en las personas independientemente de su lugar de procedencia. Tampoco reconoce género, raza ni otros; es un mal generalizado y poco señalado que está erosionando nuestro modo de ver y tratar a nuestros semejantes.

Al mismo tiempo esta corriente de pensamiento, a nivel consciente e inconsciente está afectando nuestra calidad de vida porque nos está convirtiendo en una sociedad no sólo más deshumanizada para con nuestras personas mayores, sino que también nos está convirtiendo en personas que buscamos mejorar nuestro estilo de vida (lo cual está muy bien) pero basándonos en las razones equivocadas (lo cual no está tan bien).

Es así como hacer ejercicio, comer saludable, descansar lo suficiente, entre otras actitudes y acciones en nuestro estilo de vida se fundamentan en el objetivo de NO envejecer y vivir más años. ¿Queremos encontrar la fuente de la eterna juventud porque lo viejo huele, sabe, se ve, se siente y se escucha mal! Es mejor ser eternamente joven y ese es el propósito: no envejecer.

Grave equivocación: envejecemos todos los días sin excepción. La clave está en hacerlo con inteligencia. Es así como el primer paso es desterrar todos los mitos y estereotipos con relación al envejecimiento. Ver y entender el envejecimiento como algo natural, un proceso que forma parte de nuestra vida y que nos toca a todas y todos.

Una vez logrado este cometido en cuanto a nuestra percepción y asimilación de lo que es el envejecer con respecto a nosotros y a quienes nos rodean (y que al fin y al cabo son socios estratégicos en el mejoramiento de nuestro estilo de vida), nos corresponde la tarea de enfocar el mismo como un viaje hacia adelante en el cual establezcamos las acciones en todos las áreas componentes de la calidad de vida, bajo la premisa de no sólo vernos y 
sentirnos bien ahora, sino también mañana, pasado, a los 60,70 y más.....

Cuando nos dejamos llevar por estereotipos negativos con relación a la edad y al envejecimiento, caemos en el error de no poder ver el bosque por enfocarnos en ver el árbol (¡a propósito del pobre Guanacaste!) y entonces perdemos las perspectiva integral que nos permite contar con razones realistas para entender, motivar y promocionar el por qué es importante que nos cuidemos y tengamos un estilo de vida saludable.

Y es que siendo la edad un reflejo no sólo de la cantidad sino también de la calidad de los años vividos no podemos pensar que nos cuidamos para vernos jóvenes o sentirnos bien ahora...tenemos que pensar en que nos cuidamos para vernos y sentirnos bien ahora y también cuando estemos más viejas y viejos; o lo que es lo mismo, todos los días de nuestra vida.

Es entonces cuando envejecemos con verdadero sentido, pertenencia y posesión del cuerpo que habitamos y no sólo lo hacemos como una situación irremediable y sin control. Es entonces cuando logramos envejecer como si este es un viaje de disfrute y placer en el cual nos reconocemos y somos reconocidos por nuestros años en término de conocimiento, experiencia y capacidad. Es entonces cuando envejecer se vuelve algo positivo y ser un Guanacaste es símbolo de ser intocable y no poder ser derribado. Es envejecer con eficiencia y efectividad ya que sabemos que cada vez somos un mejor producto, que nos reinventamos y que valemos más y no menos.

Envejecemos en forma eficiente y efectiva cuando, sacamos el mayor provecho de lo que tenemos a nuestro alrededor, con base en lo vivido y de cara al futuro; pero con la tranquilidad de que estamos haciendo todo lo posible, en el menor tiempo posible, para mejorar nuestra calidad de vida.

El reconocimiento de envejecer en forma efectiva y eficiente exige comportarse de modo tal que se respeten, defiendan y potencien los objetivos personales en nuestra vida con respecto no sólo a cuántos años deseamos vivir sino también a cómo queremos llegar a vivir cada uno de ellos. A partir de este reconocimiento podremos también dar una respuesta a las demandas y necesidades de otras personas. Esto implica sensibilizarnos y sensibilizar a otras y otros; y esto nos exige asertividad.

La asertividad es un término ampliamente nombrado en disciplinas relacionadas con la conducta humana. En este caso, es conveniente adecuar el término "asertividad" bajo una perspectiva de calidad de vida.

La asertividad en cuanto a calidad de vida, exige que tomemos decisiones basándonos en fundamentos reales y en motivaciones concretas. Es defender nuestros propios derechos, expresando lo que sentimos y pensamos de manera directa, clara y oportuna pero sin perder de vista los derechos de las demás personas y por ende, la posibilidad de que estas también puedan manifestarse en igual forma. Somos asertivos cuando nos expresamos y validamos nuestro ser y pensar y al mismo tiempo permitimos que otras y otros hagan lo 
mismo.

Es así que, con respecto a la asertividad como una estrategia en el proceso de envejecimiento, podemos decir que hay mucho por hacer. Debemos aprender a dejar de lado la dominación y el sometimiento ante las y los "anti-viejos" para transformar nuestro estilo de vida con base en una actitud asertiva, que promueva nuestro desarrollo con base en nuestra realidad y eso implica la aceptación y potenciación de nuestra edad y envejecimiento diario.

Ser asertivo con relación al envejecimiento es un ejercicio diario que desarrolla actividades dirigidas a:

- Clarificar cómo y de qué manera envejecemos logrando la aceptación de este como un proceso diario que presenta retos y obligaciones pero también ventajas y derechos.

- Lograr un adecuado sistema de cooperación a nuestro alrededor que involucre a nuestras "socias y socios estratégicos" con respecto al proceso de envejecimiento y su relación con nuestro estilo de vida.

- Conocer y poder aplicar con éxito las estrategias y técnicas necesarias para mejorar en todas las áreas de nuestra calidad de vida, basándonos en una visión holística e integral del envejecimiento como un proceso natural y diario.

- Desarrollar una alta capacidad de influencia con respecto al tema del envejecimiento, aplicable a situaciones en el campo laboral y personal.

Desarrollar la asertividad en el tema del envejecimiento es sumamente importante. La persona que es asertiva, logra ampliar su radio de influencia, se tenga o no personas a cargo en el ámbito personal y/o laboral y si logramos este cometido, a nivel personal así como con las y los que nos rodean, probablemente estaremos desarrollando una poderosa vacuna contra las y los "anti-viejos".

Si analizamos la frase de John Searle: "La educación tiene que ver con enseñar a la gente a pensar con calidad", en el contexto de lo que se ha planteado en este escrito, no se puede pensar en mejor foro que la Universidad para proclamar la importancia que tiene el que desde nuestros espacios de vida universitaria, fomentemos el entendimiento y mensaje claro y verdadero no sólo del conocimiento sino de las actitudes y valores que darán una formación integral verdadera, no sólo a todas y todos nuestros estudiantes sino a todas y todos los que hacemos Universidad.... ¡Envejecer en forma asertiva, con dignidad y orgullo para mejorar nuestra calidad de vida como un árbol de Guanacaste es una forma de pensar con claridad! 